\title{
A Church-Based Intervention to Change Attitudes about Physical Activity among Black Adolescent Girls: A Feasibility Study
}

\author{
Wanda M. Thompson, Ph.D., R.N., W.H.N.P.-B.C. ${ }^{1}$, Diane Berry, Ph.D., C.A.N.P. ${ }^{1}$, and Jie \\ Hu, Ph.D., R.N. ${ }^{2}$ \\ ${ }^{1}$ School of Nursing Carrington Hall, The University of North Carolina at Chapel Hill, Chapel Hill, \\ North Carolina \\ ${ }^{2}$ School of Nursing, University of North Carolina at Greensboro, Greensboro, North Carolina
}

\begin{abstract}
Objective-To feasibility test a 12-week church-based physical activity intervention that was culturally sensitive, age- and gender specific directed at changing attitudes of Black adolescent girls to be more physically active.
\end{abstract}

Design and Sample-A one-group pre- and posttest design was used. A convenience sample of Black adolescent girls between the age of $12-18(n=41)$.

Intervention-A 60-min 12-week church-based program that included interactive educational sessions followed by a high energy dance aerobics class was used.

\begin{abstract}
Measures-Data were collected on biophysical measures. Surveys were used to assess the following variables: attitudes, enjoyment, self-efficacy, intention, social and family support, and PA levels.
\end{abstract}

Results-Paired $t$-tests and repeated measures ANOVA revealed no significant changes in key variables. Positive changes were noted in the odds ratios for attitudes, self-efficacy, and intention. Body mass index, metabolic equivalent tasks, and fitness showed positive trends from pre to post intervention. Family support was significantly correlated with physical activity level $(p<.01)$.

Conclusions-The study showed that physical activity programs in Black churches aimed at Black adolescent girls are feasible. Participants evaluated the intervention very favorably. Family support may be a key factor in increasing physical activity levels in Black adolescent girls.

\section{Keywords}

adolescents; black; church-based intervention; girls; physical activity

Physical inactivity among Black adolescent girls contributes to many chronic health conditions including obesity, type 2 diabetes, and cardiovascular disease, which are higher in Black women than White women (American Heart Association, 2011). Kimm et al. (2006) found that physical activity in girls deceased significantly between elementary and high school years. LaFontaine (2008) found that physical activity in adolescent girls decreased from $42 \%$ in 1991 to $33 \%$ in 2005. Over half (56\%) of Black adolescent girls do 
not participate in any leisure-time physical activity and are significantly less likely to participate in organized sports than White girls (LaFontaine, 2008). Only 22\% of Black adolescent girls participate in physical activity at least $60 \mathrm{~min}$ a day on 5 or more days of the week, and only $10 \%$ participate in physical activity 7 days a week (Centers for Disease Control and Prevention [CDC], 2010). Physical inactivity among Black adolescent girls places them at increased risk of developing chronic health conditions later in life (CDC, 2008).

The literature indicates that a key focus for many intervention studies aimed at children and adolescents are school-based approaches (Beets, Beighle, Erwin, \& Huberty, 2009; Neumark-Sztainer, Story, Hannan, \& Rex, 2003; Pate et al., 2005; Robbins, Gretebeck, Kazanis, \& Pender, 2006; Stevens et al., 2005; Young, Phillips, Yu, \& Haythornthwaite, 2006). Many school-based interventions have resulted in little to no change in physical activity outside the school setting (Pate \& O'Neill, 2009). Moreover, there have been few studies conducted in Black adolescent girls. Therefore, future research is needed to identify effective and culturally appropriate interventions for this population. Further explorations of physical activity programs that are community-based and faith-based are needed that extend physical activity programs beyond the school setting and traditional academic term (Barry, Sutherland, \& Harris, 2006; Bopp, Wilcox, Laken, \& McClorin, 2009; Whitt-Glover, Hogan, Lang, \& Heil, 2008). The few studies (Go Girls!, GEM, and Barbeau) that were conducted in Black girls revealed no statistically significant results regarding increased physical activity (Barbeau et al., 2007; Resnicow, Taylor, Baskin, \& McCarty, 2005; Rochon et al., 2003). However, these studies offer some insight for consideration in designing future studies aimed at increasing physical activity of adolescent girls. Barbeau et al. (2007) found a need for physical activity programs to be offered at various times throughout the day. The Girls Health Enrichment Multisite Studies (GEMS) supported the feasibility and the importance of a culturally relevant focus in designing program for preadolescent African American girls (ages 8-10) and their parents/caregiv-ers (Rochon et al., 2003).

Physical inactivity is higher in minorities than in Whites, but a clear explanation for these differences remain unknown (CDC, 2010). Therefore, considering cultural differences in designing physical activity interventions for Black adolescent girls may be warranted. Culture is defined by Boyington et al. (2008) as the unique shared values, beliefs, and practices of a group, and can influence the behaviors of individuals by affecting their thoughts, feelings, acceptance, and adoption of health education messages. Interventions that have been culturally tailored have been shown to be more effective when they were specifically designed for the populations they serve (Belgrave et al., 2004; Corneille, Ashcraft, \& Belgrave, 2005; Dowda et al., 2004).

Health promoting programs in Black churches have proven to be beneficial and effective in meeting the needs of the Black community and reducing health disparities (Bopp et al., 2007; Isaac, Rowland, \& Blackwell, 2007). Churches can play an important role in health promotion efforts, such as promoting physical activity because of their central role in spiritual guidance, communication, social support, and networking (Isaac et al., 2007).

The Theory of Reasoned Action (TRA) was the guiding framework for this study. The theory hypothesizes that an individual's intention to engage in a given behavior is the most immediate predictor of that behavior (Montano \& Kasprzyk, 2002). Intention mediates the effects of attitudes and subjective norms, which are perceived social pressures to participate or not to participate in a behavior (Hagger, Chatzisarantis, \& Biddle, 2002). A person who has a favorable attitude toward a behavior is more likely to have stronger intentions to 
change that behavior. Intentions are influenced by social expectations (family and friends influence) and individual attitudes (Ajzen \& Fishbein, 1980; Dishman et al., 2006).

Therefore, strategies for changing the attitudes of Black adolescent girls toward being more physically active were based on the TRA (Ajzen \& Fish-bein, 1980). Other studies support that the more positive attitude a person have toward a behavior, the more likely they are to engage in it (Lewis-Moss, Paschal, Redmond, Green, \& Carmack, 2008; Lewis-Moss, Paschal, Sly, Roberts, \& Wernick, 2009; Schneider \& Graham, 2009). Strategies were directed at changing attitudes (Lewis-Moss et al., 2009; Nelson, Benson, \& Jensen, 2009) through self-monitoring, presenting physical activity as an enjoyable process, setting goals regarding physical activity, and increasing knowledge regarding the need and importance of physical activity.

\section{Research questions}

We hypothesized that the girls in the Fitness $\cdot U \cdot N$-joy (F.U.N) study would have a more positive attitude toward physical activity as demonstrated by significantly greater enjoyment, increase in fitness and activity levels, and a lower BMI from pre intervention to post intervention (Table 1). We also hypothesized that perceived expectations of others (family) and social support would be positively correlated with physical activity levels among Black adolescent girls.

\section{Methods}

\section{Design and sample}

Participants were recruited from two large urban Black churches in the south. Inclusion criteria included self-identification as Black or African American, ages of 12-18 years, and ability to read and speak English. Exclusion criteria included a medical condition that prevented participation in regular physical activity. Only two participants (insulin pump and respiratory problems) were excluded.

The Institutional Review Board (IRB) at the University of North Carolina at Greensboro approved the study. A flyer placed on the churches' communication board and JumboTron was used to invite mothers and daughters who were interested in the study to an information session.

Consent and assent were obtained and an appointment to return the following week to collect baseline data was made. Participants received a $\$ 20$ gift card after data collection at preinterven-tion and midpoint; and a $\$ 40$ gift card at post intervention, and mother's received transportation vouchers.

\section{Intervention}

The F.U.N. intervention was developed by the author specifically for Black adolescent girls and grounded in spirituality, expressive communication, and interconnectedness. The spiritual theme was taken from Proverbs 22:6: Train up a child in the way he should go; and when he is old, he will not depart from it. This theme highlighted the importance of developing a positive attitude toward healthy behaviors early in development to assure adoption and maintenance of such behaviors into adulthood. The interconnectedness and commonality were fostered in this intervention by focusing the study on Black adolescent girls. The research team members were all Black. Participants were encouraged to sign up with friends and other family members. Dance and music are considered a form of expressive communication and has been identified as an effective and enjoyable form of physical activity for Black adolescent girls (Ciccomascolo \& Grossi, 2008). 
The F.U.N project was conducted over 12 weeks for 60 min each week, divided into two 30min sessions. The first 30-min session was aimed at influencing attitude and enhancing selfefficacy and enjoyment. The topics discussed included defining physical activity, goal setting, benefits and barriers to physical activity, body image, cultural differences, women in sports, the significance of family and friends, hair maintenance, and statistics on the health of Black adolescents and women. Healthy snacks and water were provided at each session. The second 30-min session was an interactive dance aerobics class conducted by a certified aerobics instructor. Dance interventions were built on the social, cultural, and historic significance of dance in the African American community, which have been shown to be well-received by Black adolescent girls (Meriwether, Lobelo, \& Pate, 2008; Olvera, 2008).

Goal setting was a key strategy to assist participants to establish their individual goals for being physically active. All participants were encouraged to set goals that were SMART (specific, measurable, attainable, relevant, and time-specific) (Anonymous, 2010), and to write down at least one measureable goal regarding physical activity weekly.

\section{Measures}

A Physical Activity Readiness Questionnaire (PAR-Q) was used to determine the safety or possible risk of exercising prior to consent and assent (Quinn, 2008). No information from the PAR-Q was used for data. A demographic questionnaire collected information on age, grade level, home environment, annual household income, sport participation, parents' educational level, and neighborhood safety and environment. A health history profile questionnaire developed by the author elicited information about perceived health status, health history, allergies, current medical regimes, last monthly period, birth control method, and any physical or mental conditions.

Data collection occurred at preintervention, at midpoint, and postintervention. No classes were held during the data collection process because of the time requirement needed to collect data for each participant. Biophysical measures including height, weight, blood pressure, and fitness levels obtained at preintervention, midpoint, and postin-tervention. Height was measured twice in street clothes without shoes, using a stadiometer, calibrated in $1 / 8-\mathrm{cm}$ intervals, and averaged. Weights were obtained in street clothes without shoes, to the nearest $0.1 \mathrm{~kg}$. BMI percentile was calculated twice. Overweight is defined as a BMI percentile 285 th percentile and $<95$ th percentile and obesity is defined as 295 th percentile (CDC, 2009).

Blood pressure (BP) was measured twice after sitting for $15 \mathrm{~min}$ and averaged. An estimation of cardiovascular fitness based on heart rate variability was obtained with the Polar S810i Heart Rate Monitor (PHM) (Nunan et al., 2009; Polar Fitness Test, 2009). Two readings were obtained and an average of the two readings was used as the baseline for fitness (VO2 max estimation). Omron HJ-112 Digital Pocket Pedometers were used to assess physical activity levels at week 2 and week 8 of the study; as well as a goal setting strategy (i.e., walk 10,000 steps each day). The pedometers were worn from Wednesday to Wednesday to capture week-end activity.

Self-report questionnaires were collected at pre- and postintervention except for the Social Influences and Family Support Scale, which was completed only preintervention. All questionnaires used in this study were scored on a 5-point Likert scale ranging from $1=$ strongly disagree to $5=$ strongly agree except for the Social Influences Scale (SIS).

Physical activity self-efficacy was measured using a modified version of Saunders et al. (1997) 8-item Self-Efficacy Scale, which assesses confidence in ability to be physically 
active (Motl et al., 2000). Alpha coefficient was .81 for the total scale (Barr-Anderson et al., 2007; Motl et al., 2000).

The 16-item Physical Activity Enjoyment Scale (PACES) was used to measure exercise enjoyment with higher scores indicating more enjoyment (Kendzierski \& DeCarlo, 1991; Motl et al., 2001). Cronbach's alphas ranged from .81 to .88 (Kendzierski \& DeCarlo, 1991). The Attitude Scale was an 8-item questionnaire modified by Motl et al. (2000) with higher scores indicating positive attitudes. Cronbach's alpha was .72 (Felton et al., 2002). The Intention Scale was used to measure intent to be physically active. The intention scale was a 4-item scale with higher scores indicating a stronger intention to engage in physical activity. In a study by Dishman et al. (2006) adolescent girls had a Cronbach's alpha of .91.

The SIS addresses perceived expectations of others and contains 8-items based on a 4-point Likert-type scale that ranges from $1=$ strongly disagree to $4=$ strongly agree (Saunders et al., 1997). A total score is obtained by summing items, with higher scores indicating strong social support. The internal consistency reliability was .72. The test-retest correlation coefficient was .78 (Saunders et al., 1997).

A 5-item Family Support Scale (FSS) was used to assess family interpersonal support (Felton et al., 2002). The FSS is a 4-point scale that range from $1=$ none to $4=$ daily. A total score was obtained by summing items, with higher scores indicating strong social support. The Cronbach's alpha was acceptable ranging from .60 to .72 (Felton et al., 2002).

A modified version of the Adolescent Physical Activity Recall Questionnaire (APARQ) was used to assess physical activity. The APARQ is a self-report tool that lists a number of common physical activities (Booth, Okely, Chey, \& Bauman, 2002). The girls were instructed to select the activities in which they have participated during the last week and indicate the frequency and duration of each activity. Responses were converted into metabolic equivalents (METs) using of the Compendium of Physical Activities (Ainsworth et al., 2000; Booth et al., 2002). The Program Evaluation Questionnaire contains 13- items developed by the author and collected postintervention. The questionnaire was rated on a 5point Likert scale from $1=$ strongly disagree to $5=$ strongly agree and space for additional comments was available.

\section{Analytic strategy}

Data were analyzed using Statistical Package for the Social Sciences 15 software (SPSS, 2012). Descriptive statistics were calculated for age, grade, parent education, family income, and family structure. Means and standard deviations were run on all variables preintervention, midpoint, and postinter-vention. Pearson's correlation was run, examining family and social support for girl's physical activity. Repeated measures of ANOVA were run examining fitness, METs, BMI at all three time points adjusting for age.

\section{Results}

Forty-one Black adolescent girls, aged 12-18 years $(\mathrm{M}=14.2 ; \mathrm{SD} \pm 1.6)$ were recruited (Table 2). Almost one-quarter (23.17\%) of the participants attended all of the sessions and $41 \%$ missed only one session, with a retention rate of $94 \%$ for 12 -weeks of attendance.

Attrition was low with only two lost to follow-up. All (100\%) of the participants agreed that the educational sessions were helpful and informative. Almost all (91.7\%) of the participants would recommend the program to friends and family. Almost half of the participants liked dance (43.9\%) followed by basketball (31.7\%) and walking (26.8\%). The top three sports included basketball (31.7\%), track (29.3\%), and soccer (26.8\%). 
A summary of study variables is seen in Table 3 . Higher score at midpoint and post intervention on all scales except BMI indicated positive change or improvement. No significant changes were noted in Self-Efficacy, PACES, Attitude, and Intention scores. There were no significant changes in increased weekly physical activity participation, however, trends toward increased physical activity were found. Pearson's correlations were used to examine the relationships between perceived expectations of others (family) and social support with regard to physical activity levels. A significant positive correlation (.37) was noted between family support at baseline and midpoint METS scores, showing that family support was positively correlated with physical activity (see Table 4). Although there were no significant changes post intervention, there was an increase in vigorous intensity activities, defined as METS $\ 6$, from preintervention, to midpoint, to postintervention, and odds ratios showed that high baseline scores were associated with positive change post intervention.

Repeated measures ANOVA controlling for age was used to determine whether there were significant differences in fitness, METs, and BMI from week 1 to week 6 and week 12.

Fitness significantly differed after the intervention, with or without age as a covariate. METs significantly differed without age as a covariate. BMI did not significantly differ without age as a covariate; age significantly influenced BMI. The changes in these variables were in the unexpected direction as shown in Table 5.

\section{Discussion}

This study tested the feasibility of a culturally tailored physical activity program that was age and gender specific for Black adolescent girls aimed at changing their attitudes toward physical activity. Although findings from this study were not statistically significant, other studies have shown attitude to be the key influence in the formation of intentions to participate in physical activity (Dishman et al., 2006; Fila \& Smith, 2006; Shen, McCaughtry, \& Martin, 2008; Simon et al., 2004). The study found a significant relationship between baseline family support and METS midpoint scores. This is similar to the findings of a study by Dowda, Dish-man, Pfeiffer, and Pate (2007), which showed that girls with higher perceived support were more likely to have higher total METS than girls who had less perceived family support. Other studies have also shown that girls with supportive parents who model physical activity have higher physical activity levels (Bauer, Nelson, Boutelle, \& Newmark-Sztain-er, 2008; Davison \& Jago, 2009). In this study, participants with the most positive changes in selected physical activity variables from pre to post intervention were from families with higher annual incomes and higher educational levels. These findings are similar to those of other studies, which have shown that children and adolescents whose parents have higher educational levels and higher socioeconomic status are more physically active (Bauer et al., 2008; Dowda et al., 2007). Clearly, families are an important factor in adolescent physical activity, emphasizing the importance of including parents in the development and implementation of interventions aimed at increasing the physical activity of adolescents.

Positive changes were noted in self-efficacy scores pre to postintervention. Goal setting was used to help promote physical activity. Many of the participants set goals that were SMART (Anonymous, 2010). For example, goals set were to walk 1 mile on Saturdays and Sundays on the school track near their home, to walk on the tread-mill for 30 min on Tuesdays and Thursdays, and to ride bikes around their neighborhood for 20-30 min on Saturdays. One girl had a goal to increase the number of weights she was lifting from 20 to $40 \mathrm{lbs}$ by the end of the summer. Dishman et al. (2006) found that individuals with high self-efficacy set higher goals. Furthermore, when goals are set and achieved, this increases the intention to perform a specific behavior. Intention to be physically active also is related to attitude. 
There were positive changes noted in intention to engage in physical activity after the intervention. Prior studies have also shown that interventions to enhance intention are important in improving physical activity behavior (Cochrane \& Davey, 2008; Dishman et al., 2006).

The program evaluation showed that $97 \%$ of the participants enjoyed the aerobic dance classes. In fact, dance was identified as the most popular physical activity by $44 \%$ of the participants in the study. Making the program fun and enjoyable was directed at improving attitudes toward physical activity. The program received large support from the church and excellent evaluations from the participants with $92 \%$ of participants, recommending the program to friends and family. The sessions were well-attended with retention rate of $94 \%$ for the 12 weeks; $23.17 \%$ of the participants attended all of the sessions, with $41 \%$ missing only one session. Attrition was low with only two persons lost to follow-up.

Educating young girls and the community about the importance of regular physical activity is important. The preliminary findings suggest that similar programs could be implemented in other churches. Recommendations would include ensuring that cultural components are built upon and remain intact throughout implementation; working closely with church leaders and establishing a good rapport; and extending the time frame of the program and expanding the program to include other family members.

To strengthen future studies, a control group will be included. The events around summer vacation may have altered girls' physical activity levels in comparison with the regular school year. The dosage of this program was $60 \mathrm{~min}$, once per week for 12 weeks. Once a week session for 12 weeks may not have been adequate to produce changes in BMI, fitness, and physical activity levels. Time frames for other studies have ranged from 8 weeks to 24 months (Lee, 2007; Pfeiffer et al., 2006). The physical activity measures were self-reported, which may have resulted in physical activity levels being under or over reported.

Maintaining an appropriate level of physical activity is essential to prevent or reduce obesity and other health related problems. Adolescence is a period of transition in which lifelong health habits and beliefs are adopted; therefore, fostering physical activity in adolescence can help establish healthy habits that carries over into adulthood. Black adolescent girls have a higher prevalence of physical inactivity than other ethnic and gender groups. Culturally tailored physical activity programs held in Black churches for Black adolescent girls are feasible and show promise for reducing the alarming decline in physical activity during adolescence and the associated increased in prevalence of obesity, diabetes, and cardiovascular disease.

\section{References}

Ainsworth B, Haskell W, Whitt M, Irwin M, Swartz A, Strath S, et al. Compendium of physical activities: An update of activity codes and MET intensities. Medicine and Science in Sports and Exercise. 2000; 32(Suppl 9):S498-S516. [PubMed: 10993420]

Ajzen, I.; Fishbein, M. Understanding attitudes and predicting social behavior. Englewood Cliffs, NJ: Prentice-Hall; 1980.

American Heart Association. Heart disease and stroke statistics-2012 update; Circulation: Journal of The American Heart Association. 2011. p. 1-221.Retrieved from http://circ.ahajournals.org/content/ early/2011/12/15/CIR.0b013e31823ac0-46.short

Locke's goal setting theory: Understanding SMART goal setting. 2010. Retrieved from http:// www.mindtools.com/pages/article/newHTE_87.htm

Barbeau P, Johnson M, Howe C, Allison J, Davis C, Gutin B, et al. Ten months of exercise improves general and visceral adiposity, bone, and fitness in black girls. Obesity. 2007; 15(8):2077-2085. [PubMed: 17712126] 
Barr-Anderson DJ, Young DR, Sallis JF, Neumark-Sztainer DR, Gittelsohn J, Webber L, et al. Structured physical activity and psychosocial correlates in middle-school girls. Preventive Medicine. 2007; 44(5):404-409. [PubMed: 17363050]

Barry AE, Sutherland MS, Harris GJ. Faith-based prevention model: A rural African-American case study. American Journal of Health Studies. 2006; 21:148-157.

Bauer KW, Nelson M, Boutelle KN, New-mark-Sztainer D. Parental influences on adolescents' physical activity and sedentary behavior: Longitudinal findings from project Eat-II. International Journal of Behavioral Nutrition and Physical Activity. 2008; 5(12):1-7. [PubMed: 18182102]

Beets M, Beighle A, Erwin H, Huberty J. After-school program impact on physical activity and fitness: A Meta-Analysis. American Journal of Preventive Medicine. 2009; 36 (6):527-537. [PubMed: 19362799]

Belgrave F, Reed M, Plybon L, Butler D, Allison K, Davis T. An evaluation of Sisters of Nia: A cultural program for African Ameri-can girls. Journal of Black Psychology. 2004; 30(3):329_ 343.10.1177/0095798404266063

Booth ML, Okely AD, Chey T, Bauman A. The reliability and validity of the Adolescent Physical Activity Recall Questionnaire. Medicine and Science in Sports and Exercise. 2002; 34(12):19861995. [PubMed: 12471306]

Bopp M, Lattimore D, Wilcox S, Laken M, McClorin L, Swinton R, et al. Understanding physical activity participation in members of an African American church: A qualitative study. Health Education Research. 2007; 22(6):815-826.10.1093/her/cyl149 [PubMed: 17138614]

Bopp M, Wilcox S, Laken M, McClorin L. Physical activity participation in Afri-can American churches. Journal of Cultural Diversity. 2009; 16:26-31. [PubMed: 20669400]

Boyington JE, Carter-Edwards L, Piehl M, Hutson J, Langdon D, McManus S. Culture attitudes toward weight, diet, and physical activity among overweight Afri-can American girls. Preventing Chronic Disease. 2008; 5(2):1-9.

Centers for Disease Control and Prevention. Physical activity and good nutrition: Essential elements to prevent chronic diseases and obesity. 2008. Retrieved from http://www.cdc.gov/nccdphp/ publications/aag/pdf/dnpa.pdf

Centers for Disease Control and Prevention. About BMI for children and teens. 2009. Retrieved from http://www.cdc.gov/healthy-weight/assessing/bmi/childrens_bmi/about_childrens_bmi.html

Centers for Disease Control and Prevention. Youth risk behavior surveillance - United States, 2009. Morbidity and Mortality Weekly Report: Surveillance Summaries. 2010; 59(SS-5):1-142. Retrieved from http://www.cdc.gov/mmwr/pdf/ss/ss5905.pdf.

Ciccomascolo L, Grossi L. The effect of an 8-week educational curriculum and physical activity program on attitudes toward physical activity and body image of urban adolescent girls. Women in Sport \& Physical Activity Journal. 2008; 17(2):17-23.

Cochrane T, Davey RC. Increasing uptake of physical activity: A social ecological approach. The Journal of the Royal Society for the Promotion of Health. 2008; 128(1):3140.10.1177/1466424007085223 [PubMed: 18274328]

Corneille M, Ashcraft A, Belgrave F. What's culture got to do with it? Prevention programs for African American adolescent girls. Journal of Health Care for the Poor and Underserved. 2005; 16:38. [PubMed: 16327106]

Davison KK, Jago R. Change in parent and peer support across ages 9 to $15 \mathrm{yr}$ and adolescent girls' physical activity. Medicine and Science in Sports and Exercise. 2009; 41 (9):1816-1825. [PubMed: 19657287]

Dishman R, Saunders R, Felton G, Ward D, Dowda M, Pate R. Goals and intentions mediate efficacy beliefs and declining physical activity in high school girls. American Journal of Preventive Medicine. 2006; 31 (6):475-483. [PubMed: 17110077]

Dowda M, Dishman R, Pfeiffer K, Pate R. Family support for physical activity in girls from 8th to 12th grade in South Car-olina. Preventive Medicine. 2007; 44(2):153-159. [PubMed: 17157371]

Dowda M, Pate R, Felton G, Saunders R, Ward D, Dishman R, et al. Physical activities and sedentary pursuits in African American and Caucasian girls. Research Quarterly for Exercise and Sport. 2004; 75:352-360. [PubMed: 15673034] 
Felton G, Dowda M, Ward D, Dishman R, Trost S, Saunders R, et al. Differences in physical activity between black and white girls living in rural and urban areas. Journal of School Health. 2002; 72(6):250-255. [PubMed: 12212410]

Fila SA, Smith C. Applying the theory of planned behavior to healthy eating behaviors in urban Native American youth. The International Journal of Behavioral Nutrition and Physical Activity. 2006; 3:11.10.1186/1479-5868-3-11 [PubMed: 16734903]

Hagger M, Chatzisarantis N, Biddle S. A meta-analytic review of the theories of reasoned action and planned behavior in physical activity: Predictive validity and the contribution of additional variables. Journal of Sport \& Exercise Psychology. 2002; 24(1):3-32.

Isaac EP, Rowland ML, Blackwell LE. Fighting health disparities: The educational role of the African American church. Cross Currents. 2007; 57(2):261-265.

Kendzierski D, DeCarlo K. Physical Activity Enjoyment Scale: Two validation studies. Journal of Sport \& Exercise Psychology. 1991; 13(1):50-64.

Kimm SYS, Glynn NW, McMahon RP, Voorhees CC, Striegel-Moore RH, Daniels SR. Self-perceived barriers to activity participation among sedentary adolescent girls. Medicine and Science in Sports and Exercise. 2006; 38(3):534-540. [PubMed: 16540842]

LaFontaine T. Physical activity: The epidemic of obesity and overweight among youth: Trends, consequences, and interventions. American Journal of Lifestyle Medicine. 2008; 2(1):30 36.10.1177/1559827607309688

Lee I-M. Dose-response relation between physical activity and fitness: Even a little is good; more is better. Journal of the Ameri-can Medical Association. 2007; 297(19):2137-2139.10.1001/jama. 297.19.2137

Lewis-Moss R, Paschal A, Redmond M, Green B, Carmack C. Health attitudes and behaviors of African American adolescents. Journal of Community Health. 2008; 33(5):351-356. [PubMed: 18473153]

Lewis-Moss R, Paschal A, Sly J, Roberts S, Wernick S. Assessing the health knowledge, attitudes and behaviors of mid-western African American adolescents. Amer-ican Journal of Health Studies. 2009; 24:240-248.

Meriwether RA, Lobelo F, Pate RR. Themed review: Clinical interventions to promote physical activity in youth. American Journal of Lifestyle Medicine. 2008; 2(1):725.10.1177/1559827607308557

Montano, D.; Kasprzyk, D. The theory of reasoned action and the theory of planned behavior. In: Glanz, K.; Rimer, B.; Lewis, F., editors. Health behavior and health education: Theory, research, and practice. San Francisco CA: Jossey-Bass; 2002. p. 67-98.

Motl R, Dishman R, Saunders R, Dowda M, Felton G, Pate R. Measuring enjoyment of physical activity in adolescent girls. American Journal of Preventive Medicine. 2001; 21(2):110-117. [PubMed: 11457630]

Motl RW, Dishman RK, Trost SG, Saunders RP, Dowda M, Felton G, et al. Factorial validity and invariance of questionnaires measuring Social-Cognitive determinants of physical activity among adolescent girls. Preventive Medicine. 2000; 31(5):584-594. [PubMed: 11071840]

Nelson T, Benson E, Jensen C. Negative attitudes toward physical activity: Measurement and role in predicting physical activity levels among preadolescents. Journal of Pediatric Psychology. 2009; 35(1):89-98.10.1093/jpepsy/jsp040 [PubMed: 19447878]

Neumark-Sztainer D, Story M, Hannan PJ, Rex J. New moves: A school-based obesity prevention program for adolescent girls. Preventive Medicine. 2003; 37(1):41-51. [PubMed: 12799128]

Nunan D, Donovan GAY, Jakovljevic DG, Hodges LD, Sandercock GRH, Bro-die DA. Validity and reliability of short-term heart-rate variability from the Polar S810. Medicine and Science in Sports and Exercise. 2009; 41(1):243-250. [PubMed: 19092682]

Olvera AE. Cultural dance and health: A review of the literature. American Journal of Health Education. 2008; 39(6):353-359.

Pate RR, O'Neill JR. After-school interventions to increase physical activity among youth. British Journal of Sports Medicine. 2009; 43(1):14-18.10.1136/bjsm.2008.055517 [PubMed: 19019903] 
Pate R, Ward DS, Saunders R, Felton G, Dish-man R, Dowda M. Promotion of physical activity among high-school girls: A randomized controlled trial. American Journal of Public Health. 2005; 95(9):1582-1587. [PubMed: 16118370]

Pfeiffer KA, Schmitz KH, McMurray RG, Treuth MS, Murray DM, Pate RR. Physical activities in adolescent girls: Variability in energy expenditure. American Journal of Preventive Medicine. 2006; 31(4):328-331. [PubMed: 16979458]

Polar Fitness Test. Fitness tests for aerobic fitness: A 5-minute fitness test performed wait at rest. 2009. Retrieved from http://www.fitmed.com/polar/polar_fitness_test_heart_rate_mon-itors.htm

Quinn, E. PAR-Q: The physical activity readiness questionnaire: Take the PAR-Q before you start an exercise program. 2008. Retrieved from http://sportsmedicine.about.com/od/fitnessevalandassessment/qt/PAR-Q.htm

Resnicow K, Taylor R, Baskin M, McCarty F. Results of go girls: A weight control program for overweight African-American adolescent females. Obesity Research. 2005; 13(10):1739-1748. [PubMed: 16286521]

Robbins LB, Gretebeck KA, Kazanis AS, Pender NJ. Girls on the move program to increase physical activity participation. Nursing Research. 2006; 55(3):206-216. [PubMed: 16708045]

Rochon J, Klesges R, Story M, Robinson T, Baranowski T, Obarzanek E, et al. Common design elements of the girls health enrichment multi-site studies (GEMS). Ethnicity and Disease. 2003; 13(Suppl 1):S6-S14. [PubMed: 12713207]

Saunders RP, Pate RR, Felton G, Dowda M, Weinrich MC, Ward DS, et al. Development of questionnaires to measure psychosocial influences on children's physical activity. Preventive Medicine. 1997; 26(2):241-247. [PubMed: 9085394]

Schneider ML, Graham DJ. Personality, physical fitness, and affective response to exercise among adolescents. Medicine and Science in Sports and Exercise. 2009; 41(4):947-955. [PubMed: 19276837]

Shen B, McCaughtry N, Martin J. Urban adolescents' exercise intentions and behaviors: An exploratory study of a trans-contextual model. Contemporary Educational Psychology. 2008; 33(4):841-858.

Simon C, Wagner A, DiVita C, Rauscher E, Klein-Platat C, Arveiler D, et al. Intervention centred on adolescents' physical activity and sedentary behaviour (ICAPS): Concept and 6-month results. International Journal of Obesity and Related Metabolic Disorders. 2004; 28(S3):S96-S103. [PubMed: 15543228]

SPSS. SPSS software: Predictive analytics software and solutions. 2012. Retrieved from http:// www-01.ibm.com/software/analytics/spss/

Stevens J, Murray DM, Catellier DJ, Hannan PJ, Lytle LA, Elder JP, et al. Design of the trial of activity in adolescent girls (TAAG). Contemporary Clinical Trials. 2005; 26 (2):223-233. [PubMed: 15837442]

Whitt-Glover M, Hogan P, Lang MW, Heil D. Pilot study of a faith-based physical activity program among sedentary blacks. Preventing Chronic Disease. 2008; 5(2):1-9.

Young DR, Phillips JA, Yu T, Haythornthwaite JA. Effects of a life skills intervention for increasing physical activity in adolescent girls. Archives of Pediatrics and Adolescent Medicine. 2006; 160(12):1255-1261.10.1001/archpedi.160.12.1255 [PubMed: 17146023] 
TABLE 1

Constructs of Theory of Reason Action with Corresponding Measures

\begin{tabular}{llll}
\hline Concept & Variable & Measures & Data collection \\
\hline Attitude & Attitude & Attitude scale & Pre- \& post intervention \\
& Enjoyment & PACES & Pre- \& post intervention \\
Beliefs & Self-efficacy & Self-efficacy & Pre- \& post intervention \\
Intention & Intention & Intention scale & Pre- \& post intervention \\
Subjective norms & $\begin{array}{l}\text { Perceived expectations of } \\
\text { others }\end{array}$ & Family support & Pre-intervention (baseline only) \\
& Social support & Social influences & Pre-intervention (baseline only) \\
Behavior & & & \\
Physical activity & & APARQ (METs) Pedometers & Pre-, midpoint \& Post- 2nd and 8th week \\
Biophysical & & & Pre-, midpoint \& post- \\
Blood pressure & & B/P & Pre-, midpoint \& post- \\
Fitness & Polar heart monitor & Pre-, midpoint \& post- \\
BMI & Weight and height per age- and gender-specific
\end{tabular}


TABLE 2

Demographic of Participants $(\mathrm{N}=41)$

\begin{tabular}{|c|c|}
\hline Variable & Frequency $(\%)$ \\
\hline \multicolumn{2}{|l|}{ Age } \\
\hline 12 & $6(14.6)$ \\
\hline 13 & $12(29.3)$ \\
\hline 14 & $7(17.1)$ \\
\hline 15 & $7(17.1)$ \\
\hline 16 & $5(12.2)$ \\
\hline 17 & $3(7.3)$ \\
\hline 18 & $1(2.4)$ \\
\hline \multicolumn{2}{|l|}{ Grade } \\
\hline 6 & $3(7.3)$ \\
\hline 7 & $8(19.5)$ \\
\hline 8 & $8(19.5)$ \\
\hline 9 & $7(17.1)$ \\
\hline 10 & $9(22.0)$ \\
\hline 11 & $4(9.8)$ \\
\hline 12 & $2(4.9)$ \\
\hline \multicolumn{2}{|c|}{ Parents educational background } \\
\hline High school drop-out & $2(4.9)$ \\
\hline Graduated 12 th grade & $3(7.3)$ \\
\hline Some college & $8(19.5)$ \\
\hline Associated degree & $5(12.2)$ \\
\hline Bachelor degree & $16(39.0)$ \\
\hline Master's degree & $6(14.6)$ \\
\hline Ph.D. degree & $1(2.4)$ \\
\hline \multicolumn{2}{|l|}{ Family annual income } \\
\hline Less than $14,999 /$ year & $4(9.8)$ \\
\hline $15,000-24,999$ & $2(4.9)$ \\
\hline $25,000-34,999$ & $3(7.3)$ \\
\hline $35,000-49,999$ & $3(7.3)$ \\
\hline $50,000-74,999$ & $19(46.3)$ \\
\hline $75,000-99,999$ & $4(9.8)$ \\
\hline$>100,000$ & $6(14.6)$ \\
\hline \multicolumn{2}{|l|}{ Family structure } \\
\hline Two parent household & $25(61.0)$ \\
\hline Single parent household & $15(36.6)$ \\
\hline Other & $1(2.4)$ \\
\hline
\end{tabular}

Public Health Nurs. Author manuscript; available in PMC 2013 October 01. 
TABLE 3

Summary of Variables

\begin{tabular}{lccc}
\hline Variables & $\begin{array}{c}\text { Preintervention }(\mathbf{N}=\mathbf{4 1}) \\
\text { Mean }(\mathbf{S D})\end{array}$ & $\begin{array}{c}\text { Midpoint }(\mathbf{N}=\mathbf{3 9}) \\
\text { Mean }(\mathbf{S D})\end{array}$ & $\begin{array}{c}\text { Postintervention }(\mathbf{N}=\mathbf{3 7}) \\
\text { Mean (SD) }\end{array}$ \\
\hline Fitness & $36.8(6.4)$ & $36.82(6.4)$ & $36.8(6.1)$ \\
BMI & $26.1(6.1)$ & $26.46(6.2)$ & $26.5(6.3)$ \\
METs & $51.4(37.7)$ & $51.54(40.4)$ & $40.5(29.5)$ \\
Attitude scale & $32.2(4.1)$ & - & $32.1(3.8)$ \\
PACES (Enjoyment) & $63.9(9.4)$ & - & $64.5(6.8)$ \\
Self-efficacy scale & $29.3(5.6)$ & - & $28.9(4.7)$ \\
Intention scale & $14.7(3.5)$ & - & $14.9(2.4)$ \\
Family support scale & $9.1(3.8)$ & - & $9.1(3.0)$ \\
Social support scale & $22.7(4.2)$ & - & $22.6(4.6)$ \\
\hline
\end{tabular}




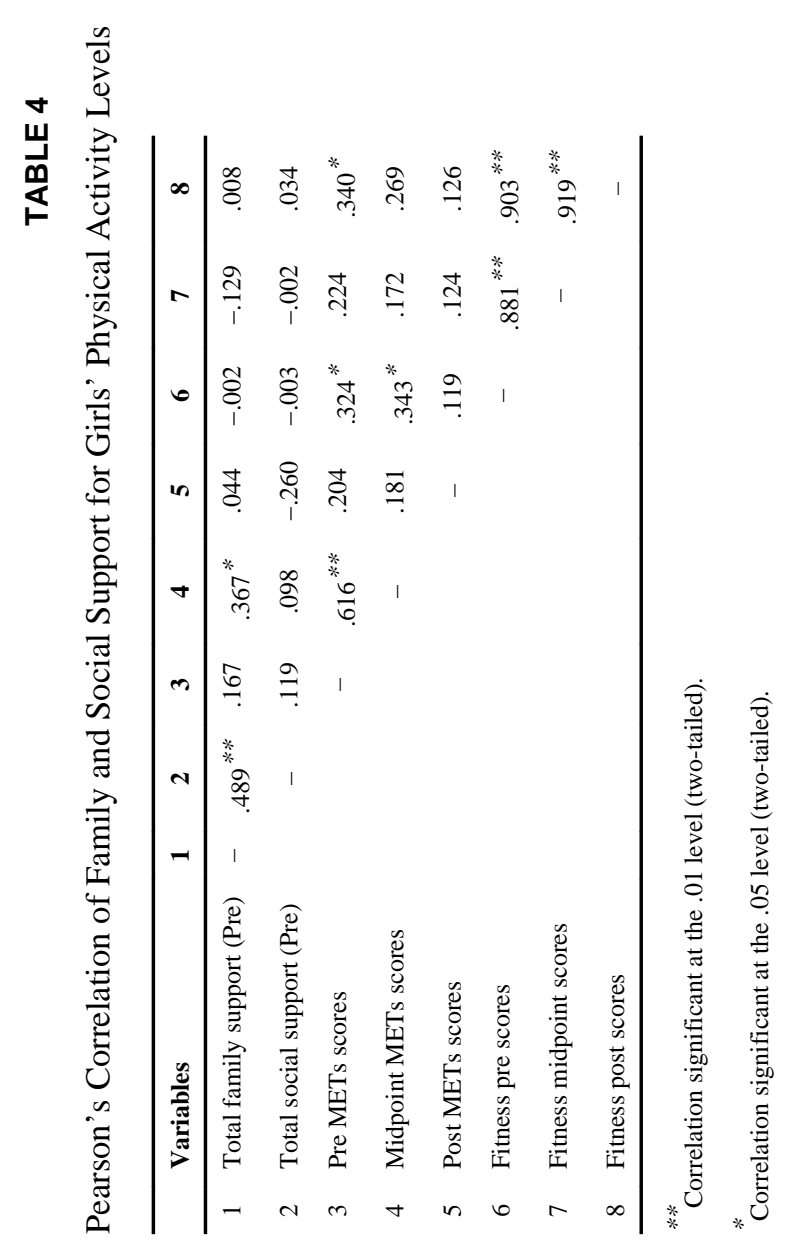

Public Health Nurs. Author manuscript; available in PMC 2013 October 01. 


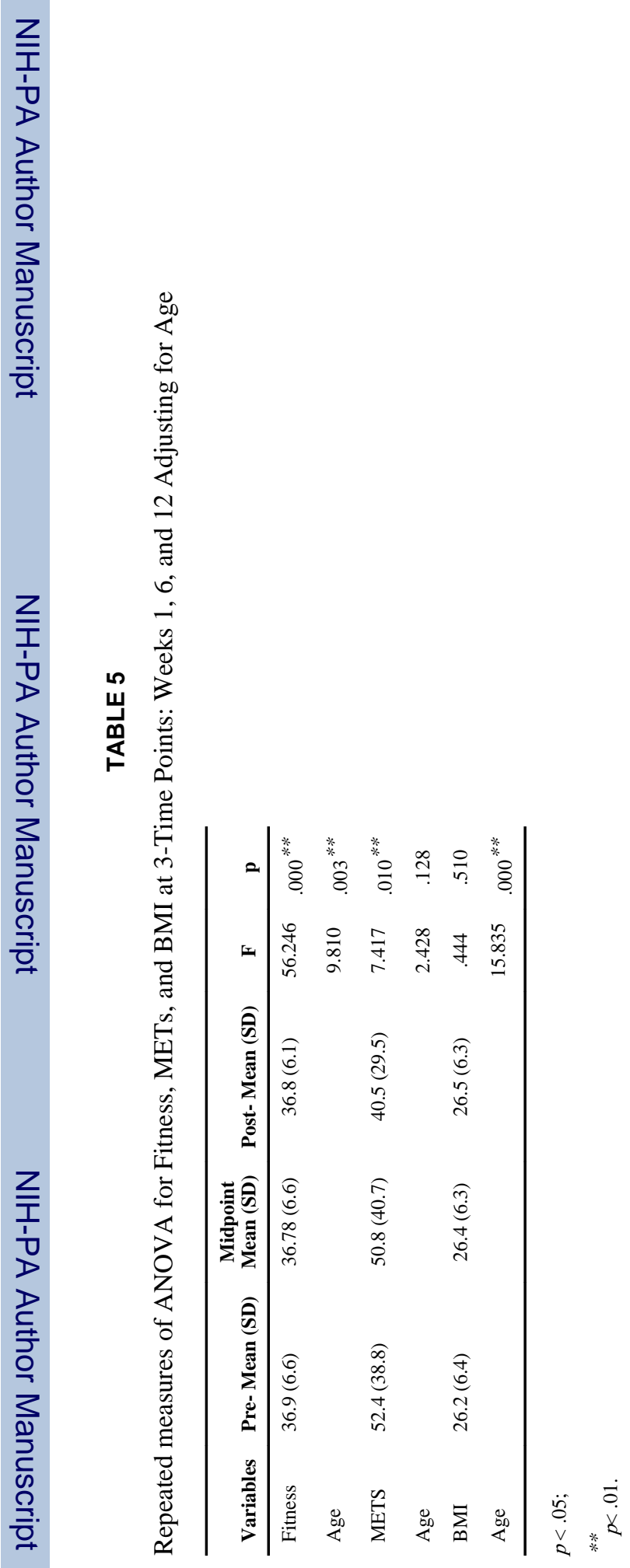

